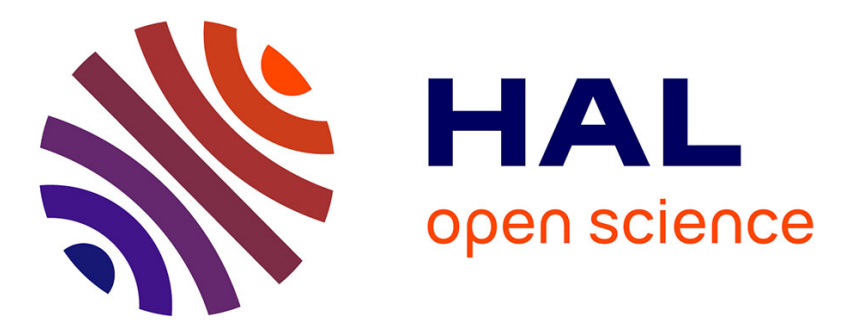

\title{
A Propagation Model for Trees Based on Multiple Scattering Theory
}

\author{
J. Israel, F. Lacoste, H.J. Mametsa, F.P. Fontan
}

\section{To cite this version:}

J. Israel, F. Lacoste, H.J. Mametsa, F.P. Fontan. A Propagation Model for Trees Based on Multiple Scattering Theory. 8th European Conference on Antennas and Propagation (EUCAP 2014), Apr 2014, LA HAYE, Netherlands. pp.1255 - 1258, 10.1109/EuCAP.2014.6902004 . hal-01058669

\section{HAL Id: hal-01058669 \\ https://hal-onera.archives-ouvertes.fr/hal-01058669}

Submitted on 8 Oct 2014

HAL is a multi-disciplinary open access archive for the deposit and dissemination of scientific research documents, whether they are published or not. The documents may come from teaching and research institutions in France or abroad, or from public or private research centers.
L'archive ouverte pluridisciplinaire HAL, est destinée au dépôt et à la diffusion de documents scientifiques de niveau recherche, publiés ou non, émanant des établissements d'enseignement et de recherche français ou étrangers, des laboratoires publics ou privés. 


\title{
A Propagation Model for Trees Based on Multiple Scattering Theory
}

\author{
Jonathan Israel ${ }^{1}$, Frederic Lacoste ${ }^{2}$, Henri-José Mametsa ${ }^{3}$, Fernando P. Fontan ${ }^{4}$ \\ ${ }^{1}$ ONERA - The French Aerospace Lab, Toulouse, France, Jonathan.Israel@onera.fr \\ ${ }^{2}$ CNES, Toulouse, France, Frederic.Lacoste@cnes.fr \\ ${ }^{3}$ ONERA - The French Aerospace Lab, Toulouse, France, Henri-Jose.Mametsa@onera.fr \\ ${ }^{4}$ Departamento de Teoría de la Señal y Comunicaciones, Universidade de Vigo, Vigo, Spain, fpfontan@tsc.uvigo.es
}

\begin{abstract}
Based on the multiple scattering theory, we derive a point scattering propagation model which allows an efficient computation of the diffuse component of the electromagnetic field scattered by a vegetation canopy. We show that our mode is in good agreement both with the original multiple scattering predictions and with measurements.
\end{abstract}

Index Terms-Vegetation, Propagation, Multiple Scattering Theory.

\section{INTRODUCTION}

In order to characterize the scattering effects due to trees with an acceptable complexity level, several electromagnetic models have been used (Multiple Scattering Theory [1], Radiative Transfert Theory [2], Volume Integral Equation [3]). Since its introduction by Twersky in 1967, the Multiple Scattering Theory has been widely applied and modernized in order to characterize various types of vegetation elements [4], [5], [6]. Branches, needles or leaves are modeled as homogeneous dielectric cylinders. Those single scatterers are located either uniformly [6], [7] or following specific schemes like fractal ones in the tree canopy [8]. The multiple scattering theory takes into account successive interactions between all scatterers, each scatterer being involved at most once in each scattering path. It results in a volumic characterization of the electromagnetic propagation properties in terms of amplitude scattering matrix, Radar Cross Section (RCS) and effective propagation constant. We derive a point scattering model that relies on those data and that is used to compute the scattering of a whole tree. Branches and leaves movements due to wind are taken into account.

\section{PRevious DEVElopments}

We introduce in this section formulas and concepts established in [9] and [7] which are necessary for the point scattering model derivation.

\section{A. Single scatterer model}

Consider a single scatterer (branch, leaf or needle) modeled as a thin dielectric cylinder in a large tree canopy, fig. 1. It is illuminated by a planar wave $\mathbf{E}_{i}$ represented at $\mathbf{r}$ as:

$$
\mathbf{E}_{i}(\mathbf{r})=\mathbf{E}_{0} e^{-j \mathbf{k} \cdot \mathbf{r}}
$$

where $\mathbf{E}_{0}$ is the incident field amplitude and $\mathbf{k}$ is the wave vector.

Karam et al. [9] showed that the scattered field $\mathbf{E}_{s}$ can be written as:

$$
\mathbf{E}_{s}(\mathbf{r})=\overline{\overline{\mathbf{F}}}(\mathbf{s}, \mathbf{i}) \cdot \mathbf{E}_{0} \frac{e^{-j k\|\mathbf{r}\|}}{\|\mathbf{r}\|}
$$

where $\mathbf{i}$ is the incident direction, $\mathbf{s}$ is the observation direction and $\overline{\overline{\mathbf{F}}}$ is the scattering amplitude matrix that characterizes the vegetation element.

\section{B. Canopy volume}

Consider now a tree canopy modeled as a cylinder which includes $N_{b}$ types of branches and one type of leaves. DeJong [7] derived the mean volumic scattering amplitude matrix $F^{e q}$ and the mean volumic RCS $\sigma^{e q}$ :

$$
\begin{array}{r}
F^{e q}(\mathbf{s}, \mathbf{i})=\sum_{b=b_{1}}^{b_{N_{b}}} \rho_{b} E\left(F^{b}(\mathbf{s}, \mathbf{i})\right)+\rho_{l} E\left(F^{l}(\mathbf{s}, \mathbf{i})\right) \\
\sigma^{e q}(\mathbf{s}, \mathbf{i})=4 \pi\left\{\sum_{b=b_{1}}^{b_{N_{b}}} \rho_{b} E\left(\left|F^{b}(\mathbf{s}, \mathbf{i})\right|^{2}\right)+\rho_{l} E\left(\left|F^{l}(\mathbf{s}, \mathbf{i})\right|^{2}\right)\right\}
\end{array}
$$

where:

- $\rho_{b}$ and $\rho_{l}$ are the branches and leaves densities,

- $F^{b}$ and $F^{l}$ are the coefficients of the scattering amplitude matrix $\overline{\overline{\mathbf{F}}}$ for branches and leaves for the considered polarization.

Besides, the effective propagation constant in the canopy is given by:

$$
K(\mathbf{i})=k+\frac{2 \pi}{k} F^{e q}(\mathbf{i}, \mathbf{i})
$$

\section{Diffuse component of the scattered field}

Following Twersky's theory, [7], the diffuse (or incoherent) component $E_{s}^{\text {incoh }}$ of the field scattered by the whole canopy at $\mathbf{r}$ is such that:

$$
E\left(\left|E_{s}^{i n c o h}(\mathbf{r})\right|^{2}\right)=\iiint_{V}\left|V\left(\mathbf{r}, \mathbf{r}^{\prime}\right)\right|^{2} E\left(\left|E_{i n}\left(\mathbf{r}^{\prime}\right)\right|^{2}\right) d V^{\prime}
$$

where $E_{i n}\left(\mathbf{r}^{\prime}\right)$ is the incident field at a location $\mathbf{r}^{\prime}$ inside the canopy and $V\left(\mathbf{r}, \mathbf{r}^{\prime}\right)$ is given by:

$$
V\left(\mathbf{r}, \mathbf{r}^{\prime}\right)=4 \pi F^{e q}(\mathbf{s}, \mathbf{i}) G_{0}\left(\mathbf{r}, \mathbf{r}^{\prime}\right) e^{-j(K-k) s_{2}\left(\mathbf{r}^{\prime}\right)}
$$




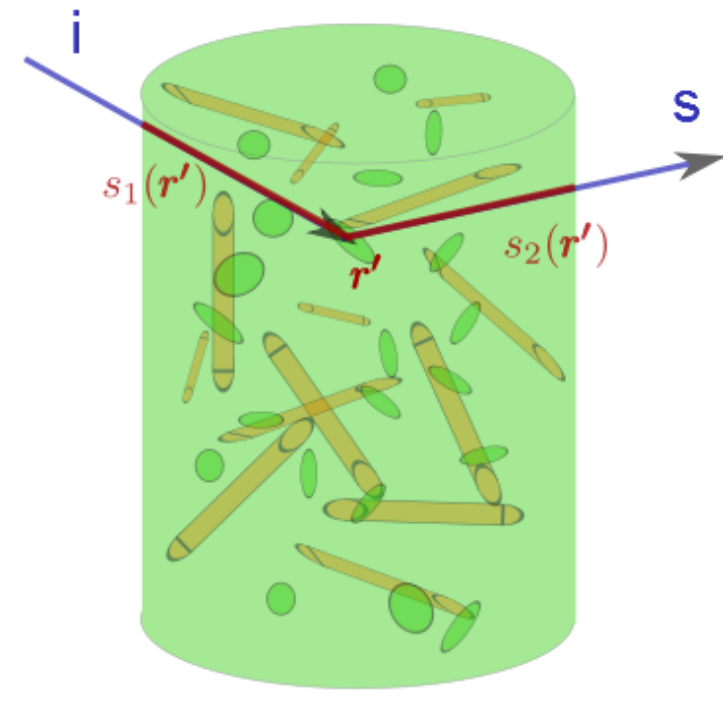

Fig. 1. Cylindrical canopy composed of branches and leaves.

where $G_{0}\left(\mathbf{r}, \mathbf{r}^{\prime}\right)$ is the free-space Green function:

$$
G_{0}\left(\mathbf{r}, \mathbf{r}^{\prime}\right)=\frac{e^{-j k\left\|\mathbf{r}-\mathbf{r}^{\prime}\right\|}}{4 \pi\left\|\mathbf{r}-\mathbf{r}^{\prime}\right\|}
$$

The mean incident field $E\left(E_{i n}\right)$ at $\mathbf{r}^{\prime}$ is:

$$
E\left(E_{i n}\left(\mathbf{r}^{\prime}\right)\right)=E_{i}\left(\mathbf{r}^{\prime}\right) e^{-j(K-k) s_{1}\left(\mathbf{r}^{\prime}\right)}
$$

In (6) and (8), $s_{1}\left(\mathbf{r}^{\prime}\right)$ (resp. $s_{2}\left(\mathbf{r}^{\prime}\right)$ ) corresponds to the distance between each scatterer and the canopy boundary in the incoming (resp. observation) direction.

\section{Point SCATtering MOdel}

In this section, we present an equivalent scattering model which allows us to generate different trees while ensuring that their average scattering remains the same as in the multiple scattering model.

\section{A. Parameters derivation}

Point scattering models have already been used in order to model the canopy scattering effect, for instance at Lband by Schubert et al. [10], [11]. The basic idea is to set $N_{\text {dif }}$ punctual scatterers in the canopy such that their mean scattering contribution will be equal to the incoherent component given in (5). For each point scatterer $d_{i}$ located in $\mathbf{r}_{i}^{\prime}$, the electromagnetic field scattered at $\mathbf{r}$ is:

$$
E_{s, i}(\mathbf{r})=\frac{e^{-j k\left\|\mathbf{r}-\mathbf{r}^{\prime}{ }_{i}\right\|}}{\left\|\mathbf{r}-\mathbf{r}^{\prime}{ }_{i}\right\|} A_{i} e^{j \phi_{i}} E_{i n}\left(\mathbf{r}_{i}^{\prime}\right)
$$

where:

- $E_{\text {in }}\left(\mathbf{r}_{i}^{\prime}\right)$ is the equivalent incoming field,

- $A_{i}$ is the scatterer amplitude,

- $\phi_{i}$ is the scatterer phase.

We consider separately each branch or leaf type for which the scatterer amplitude is constant:

$$
A_{i}=A_{d} \forall i \in\left\{1, \ldots, N_{\text {dif }}\right\}
$$

If we consider that $\mathbf{r}$ is located in the far field of the tree, we have in the amplitude term of (9):

$$
\left\|\mathbf{r}-\mathbf{r}_{i}^{\prime}\right\| \approx\left\|\mathbf{r}-\mathbf{r}_{0}^{\prime}\right\| \quad \forall i \in\left\{1, \ldots, N_{d i f}\right\}
$$

where $\mathbf{r}_{0}^{\prime}$ is located at the center of the canopy.

By replacing the tree canopy by point scatterers, the equivalent incoming field is constant:

$$
E_{\text {in }}\left(\mathbf{r}^{\prime}{ }_{i}\right)=E_{\text {in }}\left(\mathbf{r}^{\prime}{ }_{0}\right) \forall i \in\left\{1, \ldots, N_{\text {dif }}\right\}
$$

By substituting (10), (11) and (12) in 9, we obtain:

$$
E_{s, i}(\mathbf{r})=\frac{e^{-j k\left\|\mathbf{r}-\mathbf{r}^{\prime}{ }_{i}\right\|}}{\left\|\mathbf{r}-\mathbf{r}^{\prime}{ }_{0}\right\|} A_{d} e^{j \phi_{i}} E_{i n}\left(\mathbf{r}^{\prime}{ }_{0}\right)
$$

The electromagnetic field at $\mathbf{r}$ due to the scattering of the set of scatterers is:

$$
E_{s}(\mathbf{r})=\sum_{i=1}^{N_{d i f}} E_{s, i}(\mathbf{r})
$$

The RCS $\sigma_{N_{d i f}}$ for the set of all scatterers is:

$$
\sigma_{N_{d i f}}=4 \pi\left\|\mathbf{r}-\mathbf{r}_{0}^{\prime}\right\|^{2} \frac{\left|E_{s}(\mathbf{r})\right|^{2}}{\left|E_{\text {in }}\left(\mathbf{r}_{0}^{\prime}\right)\right|^{2}}
$$

So finally:

$$
\sigma_{N_{d i f}}=4 \pi A_{d}^{2} X^{2}
$$

where:

$$
\begin{array}{r}
X=\left|\sum_{i=1}^{N_{d i f}} e^{j \psi_{i}}\right| \\
\psi_{i}=\phi_{i}-k\left\|\mathbf{r}-\mathbf{r}^{\prime}{ }_{i}\right\|
\end{array}
$$

Since $\phi_{i} \sim U\left(\left[\begin{array}{ll}0 & 2 \pi\end{array}\right]\right)$ and $\left\{\mathbf{r}_{i}\right\}_{i \in\left\{1, \ldots, N_{d i f}\right\}}$ are uniformly distributed in the canopy, $\psi_{i} \sim U\left(\left[\begin{array}{ll}0 & 2 \pi\end{array}\right]\right)$. So $X$ follows a Rayleigh low with $\sigma$ parameter such that:

$$
\sigma=\sqrt{\frac{N_{d i f}}{2}}
$$

$X$ mean value $\mu_{X}$ and variance $\sigma_{X}^{2}$ are:

$$
\begin{array}{r}
\mu_{X}=\sigma \sqrt{\frac{\pi}{2}}=\sqrt{\frac{N_{d i f} \pi}{4}} \\
\sigma_{X}{ }^{2}=\frac{4-\pi}{2} \sigma^{2}=\frac{N_{d i f}(4-\pi)}{4}
\end{array}
$$

From (19) we have:

$$
E\left[X^{2}\right]=N_{d i f}
$$

From (15) and (20), we derive the mean RCS for the set of scatterers:

$$
E\left[\sigma_{N_{d i f}}\right]=4 \pi A_{d}^{2} N_{d i f}
$$

We obtain from (21) the constant amplitude for all scatterers of each branch or leaf type:

$$
A_{d}=\sqrt{\frac{E\left[\sigma_{N_{d i f}}\right]}{4 \pi N_{d i f}}}
$$

We give in fig. 2 the mean RCS computed either by the multiple scattering theory or the point scattering method for 

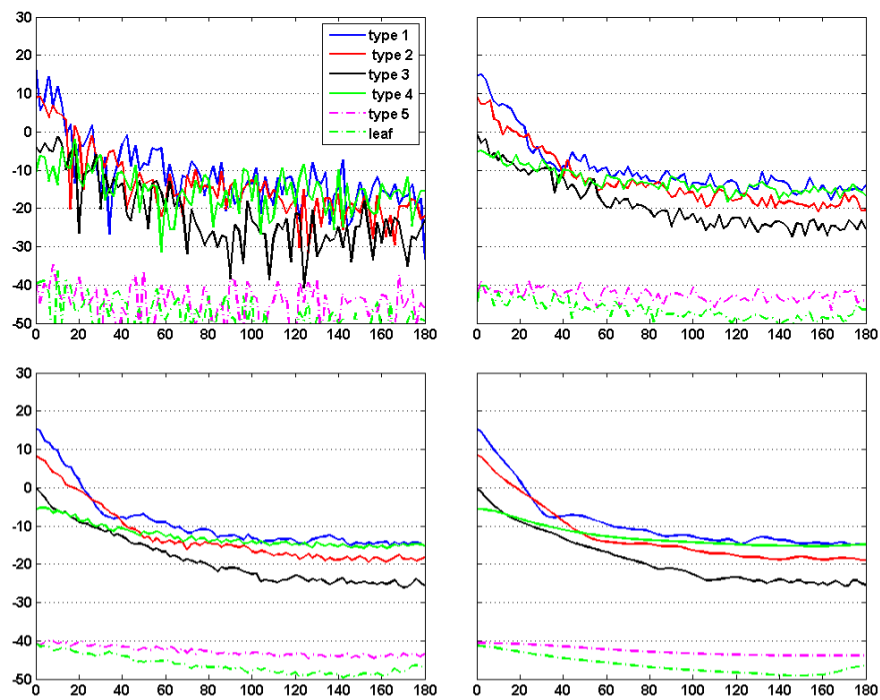

Fig. 2. Mean RCS (in dB) w.r.t. the observation azimuth angle (in degree) computed on 1 (top left), 10 (top right) and 100 (bottom left) trees by the point scattering model. The reference value computed by the multiple scattering theory is shown on the bottom right picture.

1, 10 and 100 Monte Carlo samples. We use 10 point scatterers for each branch or leaf type. Thanks to its definition in (17) and to the central limit theorem, $X$ converges in $\sigma \sqrt{N}$ toward its mean value ( $N$ being the number of Monte Carlo samples), ensuring a good convergence to the point scattering model RCS toward the multiple scattering RCS computed with (3).

\section{B. Wind models}

High frequency fading due to swaying can be taken into account easily in the point scattering model. The wind turbulent behavior is represented by a mass-spring system, [12]. The branch or leaf $i$ (or any point scatterer) moves according to the following differential equation:

$$
m_{i} \ddot{x}_{i}(t)+c_{i} \dot{x}_{i}(t)+k_{i} x_{i}(t)=f_{i}(t)
$$

where:

- $x_{i}$ is the movement,

- $t$ is the time,

- $m_{i}$ is the mass,

- $k_{i}$ is the spring constant,

- $c_{i}$ is the dumpling factor,

- $f_{i}(t)$ is the dynamic force induced by the wind.

We follow [12] in order to generate a wind model and to compute the induced force. Then, we solve (23) in order to compute the point scatterer movements.

On fig. 3, we show one tree average RCS (2s sampling at $50 \mathrm{~Hz}$ ) for a low and a high wind condition. When the wind speed is low and stable, temporal phase variations are low for all the scatterers and the averaging effect is imperceptible. In opposite, when the wind speed is high and erratic, the mean RCS is close to the reference value. However, the phase time serie of each scatterer is still not completely random due to the wind temporal coherence. So the RCS is not as close to
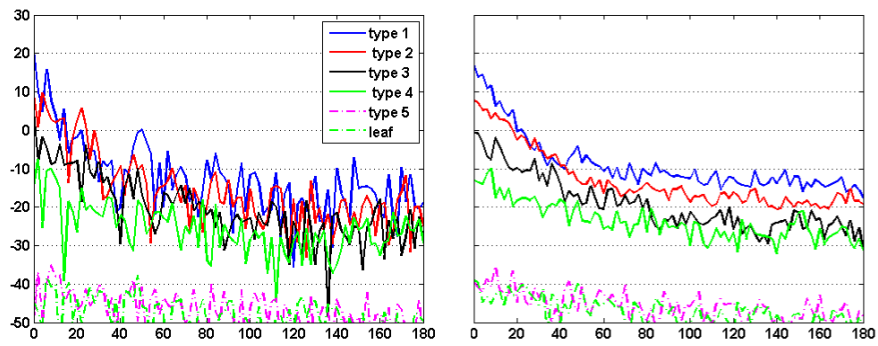

Fig. 3. Mean RCS (in dB) w.r.t. the observation azimuth angle (in degree) computed on a $2 \mathrm{~s}$ simulation sampled at $50 \mathrm{~Hz}$ during a smooth (left) and a substantive (right) windy condition.

the reference value as it is for 100 completely random samples on fig. 2.

\section{Measurements campaign}

We compare the attenuated direct power and the diffuse multipath power predicted by the multiple scattering theory and those estimated from a measurement campaign performed in Gaillac, France in 2006, [4]. Measurements have been done at $2.2 \mathrm{GHz}$ from a car-mounted antenna. Assuming a Ricean propagation canal, we estimate the shadowing and the multipath powers [13], see fig.4. The estimated positions of four trees are represented by green vertical lines. Powers are relative to the unshadowed line of sight. Based on fig. 4, we see that the mean attenuated value at tree locations is around $-10 \mathrm{~dB}$ whereas the multipath power is around $-14 \mathrm{~dB}$. We give in Table I the simulation results for the attenuated and diffuse powers w.r.t. the canopy diameter.

The precise comparison between measured data to theoretic ones is difficult due to many reasons (trunk diffraction and shadowing, ground reflection, unknown canopy geometry and size, etc.). However, orders of magnitude of the attenuated and scattered powers estimated from measurements or by the
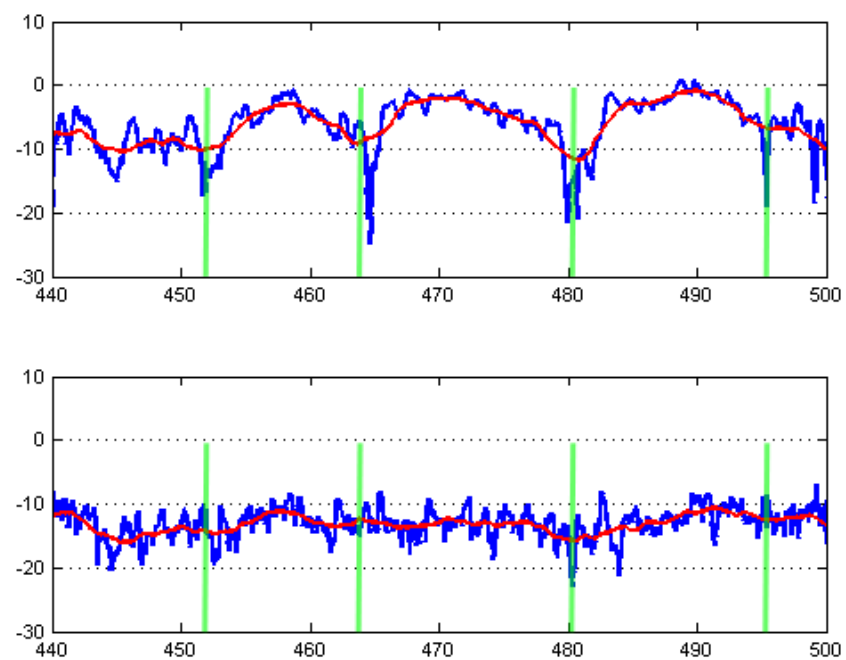

Fig. 4. Attenuated direct signal power (top) and multipath diffuse power (bottom) in $\mathrm{dB}$ estimated from measurements in Gaillac w.r.t. the distance sampling (in $\mathrm{m}$ ). Four tree positions are shown in green. 
TABLE I

ATTENUATED POWERS

\begin{tabular}{|c|c|c|c|c|}
\hline Canopy diameter $(\mathrm{m})$ & 8 & 10 & 12 & Measurment \\
\hline Attenuated power $(\mathrm{dB})$ & -7.9 & -9.8 & -11.8 & -10 \\
\hline Diffuse power $(\mathrm{dB})$ & -13.6 & -12 & -10.9 & -14 \\
\hline
\end{tabular}

multiple scattering theory are quite close.

\section{Conclusion}

Based on the multiple scattering theory, an equivalent point scattering propagation model is derived. Point scatterers are located randomly in the canopy and generate the same average diffuse field as the original method. This model can be used to generate efficiently different samples of any tree specie while taking into account wind effects.

\section{ACKNOWLEDGMENT}

This work has been financially supported by CNES study NOMADE $N^{\circ} 4500036288 / D C T 094$ and the french ANR study AMPERE $N^{\circ} 369 / 2011$.

\section{REFERENCES}

[1] V. Twersky, "Multiple scattering of electromagnetic waves by arbitrary configurations," Journal of Mathematical Physics, vol. 8, p. 589, 1967.

[2] N. Rogers, "A generic model of $1-60$ ghz radio propagation through vegetation, final report," QinetiQ, Tech. Rep. QINETIQ/KI/COM/CR020196/1.0, 2002.

[3] T. Dufva, J. Praks, S. Jarvenpaa, and J. Sarvas, "Scattering model for a pine tree employing VIE with a broadband MLFMA and comparison to ICA," IEEE Transactions on Geoscience and Remote Sensing, vol. 48, no. 3, pp. $1119-1127$, Mar. 2010.

[4] M. Cheffena, F. Fontan, F. Lacoste, E. Corbel, H. Mametsa, and G. Carrie, "Land mobile satellite dual polarized MIMO channel along roadside trees: Modeling and performance evaluation," IEEE Transactions on Antennas and Propagation, vol. 60, no. 2, pp. 597 -605, Feb. 2012.

[5] Y. de Jong and M. Herben, "A tree-scattering model for improved propagation prediction in urban microcells," IEEE Transactions on Vehicular Technology, vol. 53, no. 2, pp. 503 - 513, Mar. 2004.

[6] S. Torrico, H. L. Bertoni, and R. Lang, "Modeling tree effects on path loss in a residential environment," IEEE Transactions on Antennas and Propagation, vol. 46, no. 6, pp. 872-880, 1998.

[7] Y. de Jong, "Measurement and modelling of radiowave propagation," Ph.D. dissertation, Technische Universiteit Eindhoven, 2001.

[8] Y.-C. Lin and K. Sarabandi, "A monte carlo coherent scattering model for forest canopies using fractal-generated trees," IEEE Transactions on Geoscience and Remote Sensing, vol. 37, no. 1, pp. 440 -451, Jan. 1999.

[9] M. Karam, A. Fung, and Y. Antar, "Electromagnetic wave scattering from some vegetation samples," IEEE Transactions on Geoscience and Remote Sensing, vol. 26, no. 6, pp. $799-808$, Nov. 1988.

[10] F. M. Schubert, B. H. Fleury, P. Robertson, R. Prieto-Cerdeirai, A. Steingass, and A. Lehner, "Modeling of multipath propagation components caused by trees and forests," in 2010 Proceedings of the Fourth European Conference on Antennas and Propagation (EuCAP), Apr. 2010, pp. 1 -5 .

[11] F. M. Schubert, B. Fleury, R. Prieto-Cerdeira, A. Steingass, and A. Lehner, "A rural channel model for satellite navigation applications," in 2012 6th European Conference on Antennas and Propagation (EUCAP), Mar. 2012, pp. $2431-2435$.

[12] M. Cheffena, F. Perez-Fontan, F. Lacoste, E. Corbel, and H.-J. Mametsa, "Land mobile satellite dual polarized MIMO channel along roadside trees: Modeling and performance evaluation," in Proceedings of the 5th European Conference on Antennas and Propagation (EUCAP), Apr. 2011, pp. $3553-3558$.

[13] A. Abdi, C. Tepedelenlioglu, M. Kaveh, and G. Giannakis, "On the estimation of the $\mathrm{k}$ parameter for the rice fading distribution," Сотmunications Letters, IEEE, vol. 5, no. 3, pp. 92-94, 2001. 